\title{
Investigation of Scalar Implicatures of Binus University Students
}

\author{
Clara Herlina Karjo \\ English Department, Faculty of Language and Culture, Bina Nusantara University \\ Kemanggisan Ilir III No.45, Palmerah, Jakarta 11480, Indonesia \\ e-mail: claraherlina@yahoo.com; clara2666@binus.ac.id
}

\begin{abstract}
Scalar implicatures are based on a range of quantifiers ordered in terms of informational strength, for example in quantity: some, most, all; in frequency: sometimes, often, and always. This study measures the scalar implicatures among university students who learn English as a foreign language. The participants for this study are fourth semester English Department students at Binus University. Using the same instruments as in Slabakova (2009) and Noveck's study (2001) the present study aims to find out the general ability of the university students of computing scalar implicatures and to discover the level of pragmatic/logical competence of the university students with regards to their gender and grade point average. The results show that the students with GPA lower than three are more logical than those with GPA higher than three; while female students are more pragmatic than male students.
\end{abstract}

Key words: scalar implicatures, pragmatic, logical, gender, GPA

Human communication often involves more than what has been said or heard. The speakers often intend to convey more than the words they utter and the hearers manage to invoke the interpretation beyond the literal meaning of what they hear. In pragmatics, this is called implicature. Mei (2001) mentions that the meaning of implicature - to imply is to fold something into something else (it is from the Latin word plicare meaning 'to fold'). To achieve at the same implicature between the speakers and the hearers, Peccei (1999) mentions that there must be a considerable amount of shared knowledge between the speakers and the hearers. Consider the following example:

(1) Some lecturers are smart. 
Upon hearing this utterance, the hearers would agree that the speaker wants to convey that:

(2) Not all lecturers are smart.

The assumption in (2) is not encoded by the speaker's utterance or said by the speaker, but it is the assumption derived by the hearer based on what the speaker has said. Logically, some means some (not all) and possibly all. Notice that when we say All books are blue, it will logically entails that Some books are blue, because some is part of all. However, if the speaker of utterance (1) above had meant all lecturers are smart, she would have uttered (3):

(3) All lecturers are smart.

To arrive at the same assumption between the speaker and the hearer, Paul Grice, a philosopher of language, offered a mechanism of inferential communication. Grice (1989) proposed that all speakers, regardless of their cultural background, adhere to a basic principle governing conversation: co-operative principles, which were later known as Grice's Maxims. According to Grice's Maxims, interlocutors should speak sincerely, relevantly, clearly and provide sufficient information.

According to Grice's Maxims, in producing utterance (1) and meaning (2), the speaker has used part of the following maxims:

(4) Quantity Maxim

i. Make your contribution as informative as is required

ii. Do not make your contribution more informative than is required

Uttering the sentence (1) in most cases will communicate the assumption (2). This seems to be because the speaker does not use the stronger terms such as (3). If the speaker believes that all lecturers are smart, she would have said so. According to quantity maxim: make your contribution as informative as is required, the speaker will not use stronger term all unless required. The hearer, will also assume that stronger term does not apply.

When a speaker deliberately qualifies or scales his or her statement with language that conveys to the listeners an inference or implicature that indicates that the speaker has reasons not to choose a stronger or more informative term, s/he is making a scalar implicature. Scalar implicatures are based on a range of quantifiers ordered in terms of informational strength, for example in quantity: some, most, all; in frequency: sometimes, often, always. The basic assumption for scalar implicature is that a speaker 
will choose one that is truthful and optimally informative. In other words, the speaker will use a weaker term (e.g. some), it is an indication that the speaker chose not to articulate a more informative term from the same scale (e.g. all) (Gazdar, 1979; Horn, 1984).

Studies on how children and adults compute implicatures are numerous (Horn, 1984; Levinson, 2000; Chierchia, 2004; Noveck, 2001; Musolino \& Lidz, 2002); while scalar implicatures, according to Slabakova (2009) have not been directly tested in second language acquisition.

Following Slabakova (2009) and Noveck (2001), I carry out an investigation on the computation of scalar implicatures among university students who learn English as a foreign language. This present study has two goals. One is to find out the general ability of the university students of computing scalar implicatures. Second, is to discover the level of pragmatic/logical competence of the university students with regards to their gender and grade point average. Previously, Noveck (2001) measured the scalar implicature between children and adults; while Slabakova (2009) measured the performance of two adult native speaker groups, English and Korean and also based on the participants TOEFL scores, which were divided into Advanced and Intermediate levels. Investigations of scalar implicature based on the speakers' gender have rarely been done ; while the grade point average of the speakers is another way to group the participants based on their cognitive ability. The general purpose of this study is to find out whether female students are more pragmatic or more logical than male students and vice versa. The second purpose is to find out whether students with higher GPA (consequently 'smarter' students) are more logical or more pragmatic than students with lower GPA.

Conversational implicature derives from the shared presumption that speaker and hearer are interacting rationally and cooperatively to reach a common goal. The governing rule to achieve at appropriate implicature between the speaker and the hearer, Grice $(1989$, p. 26) offers Cooperative Principle: "Make your conversational contribution such as is required, at the stage at which it occurs, by the accepted purpose or direction of the talk exchange". This general principle is instantiated by four general maxims of conversation:

QUALITY: try to make your contribution one that is true

1. Do not say what you believe to be false.

2. Do not say that for which you lack of evidence 


\section{QUANTITY:}

1. Make your contribution as informative as is required (for the current purposes of exchange)

2. Do not make your contribution more informative than is required.

RELATION: be relevant

MANNER: be perspicuous

1. Avoid obscurity of expression

2. Avoid ambiguity

3. Be brief (avoid unnecessary prolixity)

4. Be orderly.

According to Horn (1984) all Grice's maxims (except the maxim of Quality) can be replaced with two fundamental principles:

Q (quantity) Principle (Hearer based)

Make your contribution sufficient; say as much as you can (Quantity)

R (relation) Principle (Speaker based)

Make your contribution necessary, say no more than you must (Relation, Quantity, Manner)

Grice also divides conversational implicature into two kinds. The first kind generalized conversational implicatures are those conversational implicatures which arise without requiring any particular contextual conditions. Levinson (2000) calls this generalized conversational implicatures as default inferences, that is, inferences that are automatically generated and that may be cancelled if context appears to call for it. The second kind particularized conversational implicatures are those which require such condition. Huang (2007, p. 31) gives the following examples:

(1) Generalized conversational implicature:

Most of John's friends believe in marriage

(Not all of John's friends believe in marriage)

(2) Particularized conversational implicature:

John: Where's Peter?

Mary: The light in his office is on.

(Peter is in his office)

The implicature of sentence (1) is derived from observing the maxim. Any utterance with the form "most $\mathrm{x}$ are $\mathrm{y}$ " has a default interpretation "not all $x$ are $y$ ". By contrast, the implicature in sentence (2) depends on its linguistic context. Mary's reply points to the connection between the light in Peter's office and his location. So, if the light is on, Peter must be in his office. 
One exemplary case of generalized conversational implicatures is scalar implicature. Scalar implicatures is based on the application of Grice's maxim of quantity. Levinson's theory of scalar implicatures as default GCIs argues that they exploit pre-existing scales such as (some, all), (and, or), (possible, necessary), (start, finish), etc.

Another theory of scalar implicatures comes from Sperber and Wilson (1986) and Carston (1998). They propose Relevance Theory framework. In the Relevance Theory framework, an implicature is defined as an inference that the speaker intends and expects the hearer to draw in order to arrive at an interpretation of the utterance that is relevant enough. In particular, a scalar implicature is derived when a relatively weak statement fails to meet the hearer's expectation of relevance. For example in the following dialogue:

X: Have all the students come? Y: Some are.

Y's answer is not relevant unless it is taken to implicate that some of the students have not come. According to the neo-Griceans (Levinson, 1983 ; Horn, 1984, 2006; Gazdar, 1979), scalar implicatures are automatically derived by competent language users, and can then be cancelled if the context suggest doing so, whereas for Relevance Theory scalar implicatures are derived only when they are contextually needed to achieve the expected level of relevance.

\section{METHODS}

\section{Participants}

Forty two students of semester IV English Department Bina Nusantara University participated in this study. There were 11 male students and 31 female students. These students were further divided by their grade point average (GPA). The following table shows the demography of the students.

\section{Table 1. Participants}

\begin{tabular}{llll}
\hline Gender & GPA $<3$ & GPA > 3 & Total \\
\hline Male & $8(19 \%)$ & $3(7.2 \%)$ & $11(26.2 \%)$ \\
Female & $11(26.2 \%)$ & $20(47.6 \%)$ & $31(73.8 \%)$ \\
\hline Total & $19(45.2 \%)$ & $23(54.8 \%)$ & $42(100 \%)$ \\
\hline
\end{tabular}




\section{Materials}

The experiment by Noveck (2001) served as a model. Sentences were based on three types of information : factually universal ( that elephants have trunks is represented by the quantifier all), factually existential (that birds live in cages is represented by some), and absurd (that garages can sing is false with both quantifiers). The materials were made up of 40 sentences that can be broken down into the following subgroups:

(a) Eight true All sentences (e.g. All elephants have trunks)

(b) Eight true (but pragmatically infelicitous) Some sentences (e.g. Some books have pages)

(c) Eight false $A l l$ sentences (e.g. All books have color pictures)

(d) Eight true (and felicitous) Some sentences (e.g. Some dresses have pocket)

(e) Four absurd All sentences (e.g. All chairs tell time)

(f) Four absurd Some sentences (e.g. Some books are good to eat)

\section{Procedures}

Participants were told that they were going to be presented a series of statements and that their job was simply say whether or not they agree with each statement. They were told that it was not a test and they would not have to explain their response. It was anticipated that the students would react to the absurd sentences with incredulity. However, the researcher gave some explanation about the difficult words and absurd sentences, and instructed the participants to respond with I do not agree whenever the participants were unsure.

\section{FINDINGS AND DISCUSSION}

The responses were coded for logical correctness. The following table shows the percentage of responses for each subgroup. 
Table 2. Percentage of Total Logical Responses Based on GPA, Gender and Previous Experience

\begin{tabular}{|c|c|c|c|c|c|c|c|}
\hline \multirow[t]{2}{*}{ Sentence type } & \multirow{2}{*}{$\begin{array}{l}\text { Correct } \\
\text { response }\end{array}$} & \multicolumn{2}{|c|}{ GPA } & \multicolumn{2}{|c|}{ Gender } & \multicolumn{2}{|c|}{$\begin{array}{l}\text { Previous } \\
\text { E-course }\end{array}$} \\
\hline & & $<3$ & $>3$ & Male & Female & Yes & No \\
\hline True $A l l$ & Agree & 78.3 & 91.3 & 77.3 & 88.3 & 83.5 & 90.9 \\
\hline False $A l l$ & Disagree & 94.1 & 98.4 & 93.2 & 97.6 & 96.8 & 95.4 \\
\hline Felicitous Some & Agree & 96.0 & 100 & 94.3 & 99.6 & 99.2 & 95.4 \\
\hline Infelicitous Some & Agree & 38.8 & 16.8 & 36.4 & 23.4 & 28.2 & 22.7 \\
\hline Absurd All & Disagree & 89.5 & 92.4 & 90.9 & 75.0 & 90.4 & 87.9 \\
\hline Absurd Some & Disagree & 86.6 & 91.3 & 88.6 & 70.5 & 93.2 & 93.2 \\
\hline
\end{tabular}

The table above shows that students generally agree with the logical response. For 'true all' sentences, more than $75 \%$ of the responses agree with the statements. Also for 'false all' sentences, almost 100\% responses disagree which are in accordance with correct response expected. The percentages of correct responses for 'absurd all' and 'absurd some' sentences are also quite high. However, the responses for 'infelicitous some' seem deviate from the others. The correct response for the 'infelicitous some' sentences should be 'Yes' or 'Agree'; but the result shows that less than $40 \%$ of responses are in line with the correct answer. Another interesting fact from the result is that students with GPA lower than 3 shows different response from students with GPA higher than 3. Overall, the responses of students with GPA lower than 3 are lower than students with GPA higher than 3. The only striking difference is in the 'infelicitous some sentences', students with lower GPA gave $38.8 \%$ responses while students with higher GPA only gave $16.8 \%$ 'agree' responses. A similar phenomenon occurs in the responses based on gender. Male students gave $36.4 \%$ 'agree' responses compared to female who gave $23.4 \%$ 'agree' responses for 'infelicitous some' sentences. Another variable, previous English experience, does not show significant difference between students who had English course before and those who had not had English course. Students with previous English experience give higher "agree" responses (28.2\%) compared to those without previous English experience $(22.7 \%)$.

The response to the 'infelicitous some' sentences is crucial in determining whether a person is more logical or more pragmatic. For example for the sentence 'Some hammers have handles', a logical person 
will answer 'agree' as some is part of all, because if all hammers have handles, logically some hammers also have handles. However, a pragmatic person will answer 'disagree' because she will think that if some hammers have handles, then some other hammers do not have handles, which will be inappropriate.

The total group result as presented in table 2 above may hide important individual differences, especially in this area of meaning computation where individuals may take different approaches to felicity. That is why individual accuracy on the infelicitous some sentences was calculated with a $75 \%$ cut-off point, or six out of eight items. If a participant chose pragmatic answers $75 \%$ and above, she was classified as a predominantly "pragmatic" individual; if a participant chose $25 \%$ and less pragmatic answers on the Infelicitous some sentences, she was classified as a "logical" individual. The tally is given in Table 3.

Table 3. Percentage of Logical Response for Individual Participant (Infelicitous Some)

\begin{tabular}{lcc}
\hline \multicolumn{1}{c}{ Groups } & $\begin{array}{c}\text { Numbers who chose } \\
\text { pragmatic answer }>\mathbf{7 5} \%\end{array}$ & $\begin{array}{c}\text { Numbers who chose } \\
\text { logical answer }>\mathbf{7 5 \%}\end{array}$ \\
\hline GPA $<3$ & $15(78.9 \%)$ & $4(21.1 \%)$ \\
GPA $>3$ & $22(95.6 \%)$ & $1(4.4 \%)$ \\
Male & $8(72.7 \%)$ & $3(27.3 \%)$ \\
Female & $28(90.3 \%)$ & $3(9.7 \%)$ \\
\hline
\end{tabular}

The table shows that generally, Binus students are 'pragmatic' individuals. Interestingly, there are some differences on the level of 'pragmaticity' among different groups. Students with GPA less than 3 are more logical than students with GPA more than 3, meaning that they are more 'pragmatic'. This can be explained that 'smarter' students usually have 'more imagination' than weaker students. For example when I asked one of them, why do you agree with some fish are made of leaves? This student explained that it could be a work of art in which there was a picture of a fish made of leaves (collages). Furthermore, this table also reveals that male students are more logical than female students. This finding confirms the idea that male is more rational than female. But this result may also due to the fact that most male students belong to the group of GPA $<3$, so their overall result will be lower than female students. 
However, these differences are not too high. A statistical computation using SPSS 17 is done to find out the significance of the relationship between the 'infelicitous some' response with GPA and gender. The following table shows the result.

Table 4. Correlation Between GPA, Gender and Infelicitous Some

\section{Correlations}

\begin{tabular}{ll|r|r|r}
\hline & & \multicolumn{1}{|c|}{ GPA } & Gender & Inf el Some \\
\hline GPA & Pearson Correlation & 1 & .228 & -.221 \\
& Sig. (2-tailed) & & .147 & .159 \\
& $\mathrm{~N}$ & 42 & 42 & 42 \\
\hline Gender & Pearson Correlation & .228 & 1 & -.180 \\
& Sig. (2-tailed) & .147 & & .255 \\
& $\mathrm{~N}$ & 42 & 42 & 42 \\
\hline Inf el Some & Pearson Correlation & -.221 & -.180 & 1 \\
& Sig. (2-tailed) & .159 & .255 & \\
& $\mathrm{~N}$ & 42 & 42 & 42 \\
\hline
\end{tabular}

The table shows a very low positive correlation between 'infelicitous some answer' with the GPA (0.159) and Gender (0.255). This means that both variables (GPA and Gender) are not significant enough in determining whether students are pragmatic or logical. Based on the survey above, most students are pragmatic.

\section{CONCLUSION}

Investigation on scalar implicature has a purpose of determining whether an individual is more pragmatic or more logical. This can be done by giving a statement such as Some cats have ears. A pragmatic individual will answer 'agree' because he will compute that 'some' means 'not all', then it will be interpreted as 'not all cats have ears', which is pragmatically infelicitous. On the other hand, a logical individual will answer 'disagree' because he will compute that 'some' is part of 'all'. Therefore this sentence can be interpreted as if all cats have ears, then some cats also have ears.

In the survey to forty-two Binus University students of English Department, the following results are obtained: Most of the students are pragmatic individuals. The total percentages based on GPA shows that $88 \%$ of the students are pragmatic and only $12 \%$ are logical. Similarly, the 
results by gender show that $85.7 \%$ are pragmatic and $14.3 \%$ are logical. These results show that most students, irrespective of their GPA or gender tend to be more pragmatic rather than logical; or in other words, they tend to draw an implicit meaning beyond the explicit linguistic meaning of an utterance. However, in further investigation regarding their GPA and gender, generally 'smarter' students (with GPA $>3$ ) and female students are more pragmatic than their counterparts. This can be explained by the fact that 'smarter' students and female students are more 'imaginative' than their fellow students.

As teachers, finding the students' pragmatic and logical ability is useful, especially in determining the teaching materials and the method for presenting materials. Different students' ability needs different approach. Language is not static, yet teaching as well as learning a language need a balanced portion of pragmatic ability and logical ability.

\section{REFERENCES}

Carston, R. (1998). Informativeness, relevance and scalar implicatures. In R. Carston, \& S. Uchida (Eds.), Relevance theory: Applications and implications (pp. 179-236). Amsterdam: John Benjamin.

Chierchia, G. (2004). Scalar implicatures, polarity phenomena, and the syntax/ pragmatics interface. In A. Belleti (Ed.), Structures and beyond (pp.141152) Oxford: Oxford University Press.

Gazdar, G. (1979). Pragmatics (implicature, presupposition and logical form). New York: Academic Press.

Grice, H. (1989). Studies in the way of words. Cambridge: Harvard University Press.

Horn, L. (1984). Toward a new taxonomy for pragmatic inference: Q-based and Rbased implicature. In D. Schriffin (Ed.), Meaning, form and use in context: Linguistic application (GURT 84) (pp. 11-42). Washington: Georgetown University Press.

Horn, L. R. (2006). Implicature. In L. Horn, \& G. Ward (Eds.), The handbook of pragmatics (pp. 3-28). Oxford: Blackwell Publishing.

Huang, Y. (2007). Pragmatics. Oxford: Oxford University Press

Levinson, S. (1983). Pragmatics. Cambridge: Cambridge University Press

Levinson, S. (2000) Presumptive meanings. Cambridge : MIT Press 
Mei, J. (2001). Pragmatics: An introduction. Oxford: Blackwell.

Musolino, J., \& Lidz, J. (2002). Preschool logic: Truth and felicity in the acquisition of quantification. In B. Skarabela, \& S. Fish (Eds.), The 26th Boston university conference on language development (pp. 406-416). Sommervile: Cascadila.

Noveck, I. A. (2001). When children are more logical than adults: experimental investigations of scalar implicature. Cognition, 78, 165-188.

Peccei, J. S. (1999). Pragmatics. London: Routledge.

Slabakova, R. (2009). Scalar implicatures in second language acquisition. Retrieved January 10, 2010, from http://www.sciencedirect.com

Sperber, D., \& Wilson, D. (1986). Relevance: Communication and cognition. Oxford: Basil Blackwell. 